\title{
CPNE1 silencing inhibits the proliferation, invasion and migration of human osteosarcoma cells
}

\author{
ZHENHUAN JIANG $^{1 *}$, JIANNONG JIANG ${ }^{1 *}$, BIZENG ZHAO $^{2 *}$, HUILIN YANG ${ }^{3 *}$, YUNLIANG WANG $^{4 *}$, \\ SHANG GUO $^{2 *}$, YOUPING DENG ${ }^{5}$, DEYI LU ${ }^{6}$, TIELIANG MA ${ }^{7}$, HONGWEI WANG $^{8}$ and JINZHI WANG ${ }^{9}$ \\ ${ }^{1}$ Department of Orthopaedics, Affiliated Yixing Hospital of Jiangsu University, Yixing, Jiangsu 214200; \\ ${ }^{2}$ Department of Orthopedics, Affiliated Sixth People's Hospital of Shanghai JiaoTong University, Shanghai 20023; \\ ${ }^{3}$ Department of Orthopaedics, The First Affiliated Hospital of Soochow University, Suzhou, Jiangsu 215200; \\ ${ }^{4}$ Department of Neurology, The 148 Central Hospital of PLA, Zibo, Shangdong 255000, P.R. China; ${ }^{5}$ Bioinformatics Core, \\ Department of Complementary and Integrative Medicine, University of Hawaii John A. Burns School of Medicine, Honolulu, \\ HI 96813; ${ }^{6}$ Department of Bioengineering, University of Illinois at Chicago, Chicago, IL 60607, USA; ${ }^{7}$ Central Laboratory, \\ Affiliated Yixing Hospital of Jiangsu University, Yixing, Jiangsu 214200; ${ }^{8}$ Shanghai Realgen Biotech Inc., \\ Pudong New District, Shanghai 203215; ${ }^{9}$ Department of Cell Biology, School of Medicine, \\ Soochow University, Suzhou, Jiangsu 215007, P.R. China
}

Received June 12, 2017; Accepted November 13, 2017

DOI: $10.3892 / o r .2017 .6128$

\begin{abstract}
Osteosarcoma (OS) is the most common primary malignancy of the bone affecting children and adolescents. Copine 1 (CPNE1) is a highly conserved calcium-dependent phospholipid-binding protein and may function in regulating signal transduction and membrane trafficking. In the present study, we investigated CPNE1 expression in osteosarcoma tissues and cells, and studied the effects of small interfering RNA (siRNA)-targeting CPNE1 on proliferation, metastasis and chemosensitivity of the osteosarcoma cells. The results demonstrated that CPNE1 was highly expressed in the osteosarcoma tissues and cell lines. Moreover, functional investigations confirmed that CPNE1 knockdown significantly inhibited cell proliferation, colony formation, invasion and metastasis in Saos-2 and HOS cells. Western blot analysis indicated that $C P N E 1$ silencing downregulated the expression of many proteins associated with tumorigenesis and development, including Ras, MEK-1/2, WNT1, $\beta$-catenin, cyclin A1, IRAK2 and cIAP2. In addition, CPNE1 downregulation enhanced the sensitivity of Saos-2 cells towards cisplatin and adriamycin.
\end{abstract}

Correspondence to: Dr Jinzhi Wang, Department of Cell Biology, School of Medicine, Soochow University, Suzhou, Jiangsu 215007, P.R. China

E-mail: 451588568@qq.com

Dr Hongwei Wang, Shanghai Realgen Biotech Inc., Pudong New District, Shanghai 203215, P.R. China

E-mail:whw@realgen.org

${ }^{*}$ Contributed equally

Key words: lentivirus, RNA interference, CPNE1, osteosarcoma cells, chemosensitivity
The present study provides deep insight into the clinical use of lentiviral-mediated $C P N E 1$ silencing for osteosarcoma therapy.

\section{Introduction}

Osteosarcoma is one of the most common primary malignant bone tumors in children, young adults and adolescents $(1,2)$. Despite newly developed multi-agent chemotherapy and gradually improving surgical techniques, the prognosis for patients with metastatic osteosarcoma is still poor (3). It is important to investigate the complex molecular mechanisms and identify novel biomarkers for the treatment, diagnosis and prognosis of osteosarcoma. The copines are a widely distributed class of calcium-dependent phospholipid-binding proteins that are evolutionally conserved from Arabidopsis to Homo sapiens $(4,5)$. Copine 1 (CPNE1), a soluble calcium-dependent membrane-binding protein, is ubiquitously expressed in various tissues and organs. CPNE1 is located on chromosome $20 q 11.21$ region in humans and has several alternative splicing forms coding for the same 537-amino acid protein (6). CPNE1 has a pair of $\mathrm{C} 2$ domains (C2A and $\mathrm{C} 2 \mathrm{~B}$ ) at the N-terminus and a Von Willebrand factor A (VWA) domain (A domain) at the $\mathrm{C}$-terminus (7). It was previously reported that the $\mathrm{C} 2$ domains of CPNE1 may function in cell signaling and/or membrane trafficking pathways, and the A domain facilitates the binding of CPNE1 with various intracellular proteins $(8,9)$. Lentivirus-based vectors with small hairpin RNA (shRNA) have been used as a successful tool for silencing target gene expression, particularly in cancer cells, with high specificity, stability and efficiency in vitro and in vivo $(10,11)$. However, no valid evidence concerning the biological function of CPNE1 in osteosarcoma exists to date. In the present study, we successfully silenced CPNE1 expression in Saos-2 and HOS cells using RNA interference (RNAi) technology and investigated the biological role of CPNE1 in osteosarcoma. 


\section{Materials and methods}

Main reagents. Rabbit anti-human CPNE1 polyclonal antibody (cat. no. AB155675) was purchased from Abcam (Cambridge, UK); mouse anti-human antibodies to Ras (cat. no. YT2960), MEK-1/2 (cat. no. YT2715), cyclin A1 (cat. no. YT1168) and IRAK2 (cat. no. YT2392) were purchased from ImmunoWay Biotechnology Company (Plano, TX, USA); mouse antihuman antibodies to WNT1 (cat. no. YM0649), $\beta$-catenin (cat. no. YM3065) and cIAP2 (cat. no. Ym1343) were also purchased from ImmunoWay Biotechnology Company; Lipofectamine $^{\mathrm{TM}}$ 2000, TRIzol reagent and Opti-MEM were purchased from Invitrogen Corporation (Carlsbad, CA, USA); AgeI, EcoRI and SYBR-Green Master Mix kits were purchased from New England Biolabs (NEB; Beijing, China); Taq DNA polymerase was purchased from Takara Biotechnology Co., Ltd. (Dalian, China). Cisplatin (DDP) was purchased from Qilu Pharmaceutical (Hainan) Co., Ltd. (Haikou, China). Adriamycin (ADR) was purchased from the Zhejiang Haizheng Pharmaceutical Co., Ltd. (Taizhou, China).

Cell culture and tissue collection. The human osteosarcoma cell lines (Saos-2 and HOS) were purchased from the Cell Bank of the Chinese Academy of Sciences (Shanghai, China) and were identified by short tandem repeat (STR) method in 2015. Dulbecco's modified Eagle's medium (DMEM; HyClone, Logan, UT, USA) containing 10\% fetal bovine serum (FBS) was used to culture the cells. All cells were maintained at $37^{\circ} \mathrm{C}$ in a humidified atmosphere with $5 \% \mathrm{CO}_{2}$.

Twenty-five osteosarcoma and 8 cartilage tumor tissues samples were obtained from patients who underwent surgery at the Affiliated Yixing Hospital of Jiangsu University between January 2005 and December 2015. All cases had been clinically and pathologically confirmed. Immunohistochemistry was performed by using 25 samples of osteosarcoma (13 males and 12 females; mean age, 37 years) and 8 samples of cartilage tumor (4 males and 4 females; mean age, 28 years). The experimental protocols for the present study were approved by the Hospital's Protection of Human Subjects Committee.

Immunohistochemistry. Paraffin-embedded histological specimens were cut into $4-\mu \mathrm{m}$ thick sections. Then, sections were routinely dewaxed and rehydrated in xylol, and graded alcohol. Endogenous peroxidase activity was blocked with $3 \%$ hydrogen peroxide in phosphate-buffered solution (PBS) for $15 \mathrm{~min}$ and non-specific binding was blocked with $2 \%$ bovine serum for $20 \mathrm{~min}$. The slides were incubated with 1:100 diluted primary antibody against human CPNE1 for $18 \mathrm{~h}$ at $4^{\circ} \mathrm{C}$ in $2 \%$ bovine serum albumin (BSA) in PBS. The horseradish peroxidase-conjugated goat anti-rabbit IgG secondary antibody was added and incubated for $1 \mathrm{~h}$ at $37^{\circ} \mathrm{C}$. The immune reaction was developed with 3,3'-diaminobenzidine-tetrahydrochloride-dihydrate (DAB). Slides were washed with distilled water, counterstained with hematoxylin, dehydrated and mounted. All sections were observed and analyzed under a light microscope.

Lentiviral plasmid construction, lentivirus production and cell infection. The human CPNE1 (GenBank accession no. NM_003915)-specific small interfering RNA (siRNA) sequence, which was designed using online software from
Invitrogen, was 5'-CACACAACTGGTCTCATACTT-3'. The non-silencing (NS) sequence, 5'-TTCTCCGAACGTGTCA CGT-3', was used as a scrambled control (12). The following oligonucleotides were synthesized, annealed and ligated into the pGCSIL-GFP plasmid vector between the AgeI and EcoRI sites. Then, these plasmids were amplified in DH5 $\alpha$-competent Escherichia coli cells and purified using the Qiagen plasmid. Recombinant lentiviruses were produced in $293 \mathrm{~T}$ cells by co-transfection of the recombinant pGCSIL-GFP vector, along with packaging plasmids, pHelper1.0 and pHelper 2.0, using Lipofectamine $^{\mathrm{TM}}$ 2000. For lentivirus transduction, the Saos-2 and HOS cells were subcultured at a density of $5 \times 10^{4}$ cells/well into 6-well culture plates. After growing to $30 \%$ confluence, the recombinant lentiviruses were transfected into cells at a multiplicity of infection (MOI) of 20. Each cell line was divided into the following groups: the scr-siRNA (cells infected with Lv-si-CTRL) and the CPNE1-siRNA group (cells infected with Lv-si-CPNE1). At $48 \mathrm{~h}$ post infection, the infection efficiencies were determined using a fluorescence microscope (Leica Microsystems, Wetzlar, Germany). CPNE1knockdown efficiency was evaluated by quantitative reverse transcription-polymerase chain reaction (RT-qPCR) and western blot analysis.

RNA extraction and RT-PCR. Total RNA was extracted from the cells after 5 days of infection using TRIzol reagent (Invitrogen) in accordance with the manufacturer's instructions, and then cDNA was synthesized from the total RNA. Reverse transcription was performed using M-MLV reverse transcriptase (Promega, Madison, WI, USA). The expression level of CPNE1 was detected by qPCR using an SYBR-Green Master Mixture (Takara Biotechnology Co.,Ltd.). qPCR was performed on a Bio-Rad Connect Real-Time PCR system. GAPDH was used as an internal control. Relative gene expression levels were calculated using $2^{-\Delta \Delta C t}$ analysis. Two sets of primers were used for PCR: GAPDH forward, 5'-TGACTTCAACAGCGAC ACCCA-3' and reverse, 5'-CACCCTGTTGCTGTAGCC AAA-3'; CPNE1 forward, 5'-ACCCACTCTGCGTCCTT-3' and reverse, 5'-TGGCGTCTTGTTGTCTATG-3'.

Cellomics ArrayScan assay. Briefly, Saos-2 cells infected with the lentiviral-mediated CPNE1-siRNA or scr-siRNA were seeded into 96 -well plates at a density of $2 \times 10^{3}$ cells/ well and cultured at $37^{\circ} \mathrm{C}$ in a humidified atmosphere with $5 \%$ $\mathrm{CO}_{2}$. The infected Saos- 2 cells with green fluorescence were imaged and counted on the Cellomics ArrayScan high-content screening (HCS) reader once a day for 5 days. Each experiment was conducted at least 3 times, independently. The data were collected and analyzed to create a 5-day growth curve of the infected cells.

Methylthiazolyldiphenyl-tetrazolium bromide (MTT) assay. After lentivirus infection, the Saos-2 and HOS cells were plated in a 96-well plate at a density of $1 \times 10^{4}$ cells/well. At indicated time points, MTT was added to each well at a final concentration of $5 \mathrm{mg} / \mathrm{ml}$ and incubated with the cells at $37^{\circ} \mathrm{C}$ for an additional $4 \mathrm{~h}$. After removing the supernatants, dimethyl sulfoxide (DMSO) was added to each well to terminate the reaction. Absorbance was read at a wavelength of $490 \mathrm{~nm}$ using an ELISA reader (Bio-Rad Systems, Hercules, 
CA, USA) and data were analyzed. All experiments were performed in triplicate.

Colony formation assay. Lentivirus-transduced osteosarcoma cells were plated in 6-well plates at a density of 400 cells/well. The cell culture medium was changed every other day. After incubation at $37^{\circ} \mathrm{C}$ for 14 days, the colonies were fixed with $4 \%$ paraformaldehyde, stained with Giemsa staining (Sigma-Aldrich, St. Louis, MO, USA) for $20 \mathrm{~min}$, and rinsed with distilled water. The colonies were counted and analyzed.

Transwell migration and invasion assays. Transwell chambers (8.0- $\mu \mathrm{m}$ pore size; Costar, Cambridge, NY, USA) with Matrigel (BD Biosciences, San Jose, CA, USA) bedding were placed in 24-well plates. Briefly, $1 \times 10^{5}$ cells in serumfree DMEM were seeded into the upper compartment of the chamber. The lower compartment of the chamber was filled with $600 \mu \mathrm{l}$ DMEM containing $15 \%$ FBS as a chemoattractant. After incubation at $37^{\circ} \mathrm{C}$ for $48 \mathrm{~h}$, the non-invaded cells on the upper surface of the chamber membrane were scraped off with a cotton swab, and the successfully translocated cells were then fixed with paraformaldehyde and stained with crystal violet. The invaded cells were quantified, and images were acquired under magnification of x200 (5 randomly selected fields). Cell migration assay was also performed in the Transwell chambers following the method for the invasion assay with minor modifications: the upper compartment of the chamber was not pre-coated with Matrigel (BD Biosciences), and $5 \times 10^{4}$ cells suspended in serum-free DMEM were added to the upper chamber.

Flow cytometric analysis of cell cycle istribution. The cell cycle distribution was assessed using flow cytometry using propidium iodide (PI) staining. Briefly, lentivirus-infected Saos-2 cells were harvested, re-suspended in ice-cold PBS and fixed with $70 \%(\mathrm{v} / \mathrm{v})$ cold alcohol at $4^{\circ} \mathrm{C}$. After washing thrice in PBS, Saos-2 cells were resuspended in RNase A (Sigma)-PBS solution (100 $\mu \mathrm{g} / \mathrm{ml}$ PI and $10 \mu \mathrm{g} / \mathrm{ml}$ RNase A) and incubated in the dark at room temperature for $30 \mathrm{~min}$. The suspension was then filtered through a nylon mesh, and the DNA content of stained nuclei was analyzed using a flow cytometer (FACSCalibur; BD Biosciences) in accordance with the manufacturer's guidelines.

Western blotanalysis. Five days after infection, lentivirus-transduced Saos-2 cells were collected and lysed in RIPA buffer (100 mM Tris- $\mathrm{HCl}, 150 \mathrm{mM} \mathrm{NaCl}, 1 \%$ sodium deoxycholate, $1 \%$ Tween-20 and $0.1 \%$ SDS) containing protease inhibitor mixture. After centrifugation (5,000 rpm, $10 \mathrm{~min})$, the supernatant was collected. The protein concentration was determined by bicinchoninic acid (BCA) method. Proteins were separated by sodium dodecyl sulfate-polyacrylamide gel electrophoresis (SDS-PAGE), and then transferred onto polyvinylidene fluoride membranes (Millipore, Bedford, MA, USA). Free binding sites on the membranes were blocked with 5\% BSA at room temperature for $2 \mathrm{~h}$, and subsequently incubated with different antibodies, including anti-CPNE1 (1:1,000), anti-Ras (1:1,000), anti-MEK-1/2 (1:1,000), anti-cyclin A1 (1:1,000), and anti-IRAK2 $(1: 1,000)$, anti-WNT1 $(1: 1,000)$, anti- $\beta$-catenin $(1: 1,000)$ and anti-cIAP2 $(1: 1,000)$. The signals were detected by enhanced ECL Plus Western Blotting Detection system (Amersham Biosciences, Inc., Piscataway, NJ, USA).

Chemosensitivity assay. In vitro drug sensitivity was evaluated by MTT assay. After $72 \mathrm{~h}$ of transfection with CPNE1 siRNA or control siRNA, the Saos-2 cells in 96-well plates were treated with various concentrations of DDP $(0.009765625$, $0.01953125,0.0390625,0.078125,0.15625,0.3125,0.625$, $1.25,2.5,5$ and $10 \mu \mathrm{g} / \mathrm{ml})$ and ADR $(0.01953125,0.0390625$, $0.078125,0.15625,0.3125,0.625,1.25,2.5,5,10$ and $20 \mu \mathrm{g} / \mathrm{ml})$. Then, $20 \mu \mathrm{l}$ MTT ( $5 \mathrm{mg} / \mathrm{ml})$ was added to each well and incubated for $4 \mathrm{~h}$ at $37^{\circ} \mathrm{C}$. Subsequently, DMSO $(150 \mu \mathrm{l})$ was added to solubilize the formazan crystals. Absorbance was measured using a microplate reader at $490 \mathrm{~nm}$. The inhibition ratio (\%) and $\mathrm{IC}_{50}$ (drug concentration causing a 50\% inhibition of cell growth) were determined.

Statistical analysis. The results obtained are expressed as mean \pm standard deviations (SD) of at least 3 independent experiments. The statistical significance of differences between groups was determined by Student's t-test and one-way ANOVA using GraphPad Prism 5.0 software (GraphPad Software, Inc., San Diego, CA, USA). P<0.05 was considered statistically significant.

\section{Results}

CPNE1 is overexpressed in osteosarcoma samples. CPNE1 expression was examined in 25 samples from patients with osteosarcoma. Of the 25 patients, $21(84.00 \%)$ were noted to be positive for CPNE1 expression. As shown in Fig. 1A, CPNE1 protein was observed to be localized in the nuclei and cytoplasm of the osteosarcoma tissues (a), while it was rarely detected in the cartilage tumor tissues (b). The CPNE1 expression in the osteosarcoma tissues was significantly higher than that in the cartilage tumor tissues. These results demonstrated a correlation between CPNE1 overexpression and osteosarcoma occurrence. The lentiviral vector infection efficiency was investigated using fluorescence microscope. The results of transfection demonstrated that $>90 \%$ of the treated osteosarcoma cells exhibited green fluorescence indicative of infection (Fig. 1B). CPNE1 expression at the mRNA and protein levels were measured by qPCR and western blot assays, respectively. The results indicate that CPNE1 expression at the mRNA (Fig. 1C) and protein (Fig. 1D) levels were significantly decreased in the Saos- 2 and HOS cells compared to that in the scr-siRNA groups. Thus, these results confirmed that lentiviral-mediated RNAi efficiently downregulated or blocked CPNE1 expression.

Growth inhibition of human osteosarcoma cells by CPNE1 depletion. The effects of CPNE1-siRNA on the viability of Saos-2 and HOS cells were studied in vitro. Cellomics analysis showed that CPNE1 knockdown significantly inhibited the growth of Saos- 2 cells as compared to that observed after scrsiRNA treatment, and the difference was more pronounced in a time-dependent manner $(\mathrm{P}<0.01)$ (Fig. 2A). Although the lentiviruses were transfected into the Saos-2 cells and expressed the GFP and CPNE1 siRNA, the siRNA cannot completely knock down CPNE1 in cells or suppress total 
A a

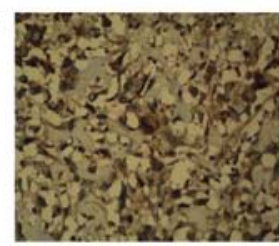

B

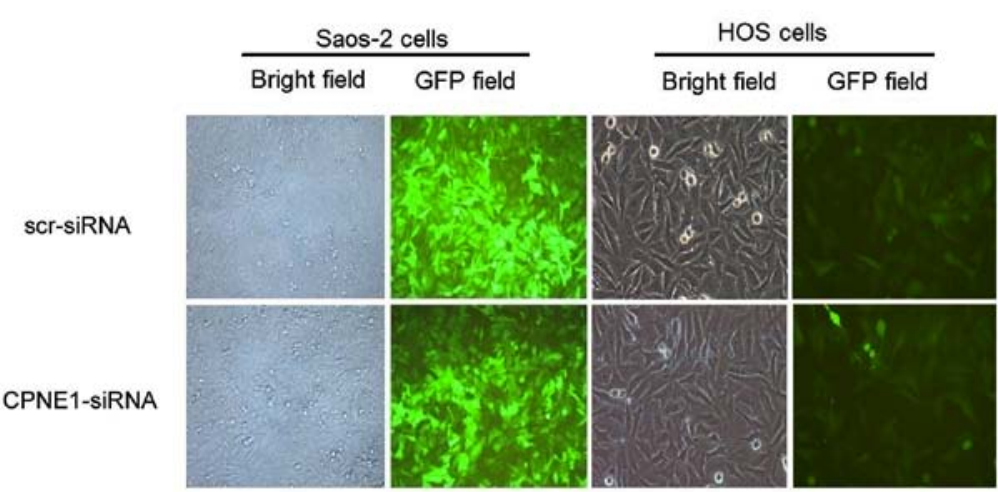

C

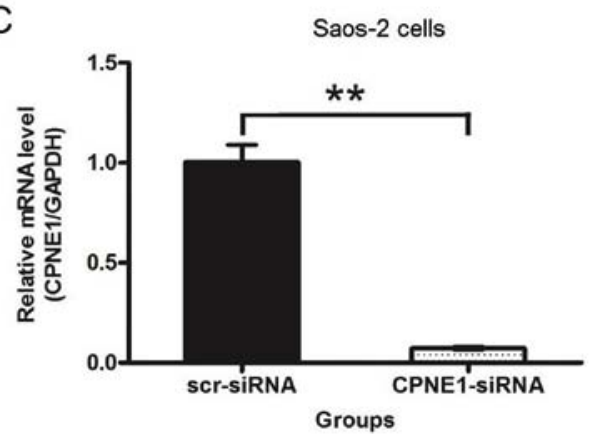

D

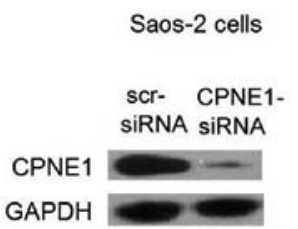

b

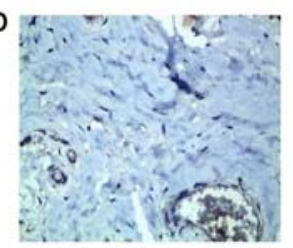

HOS cells

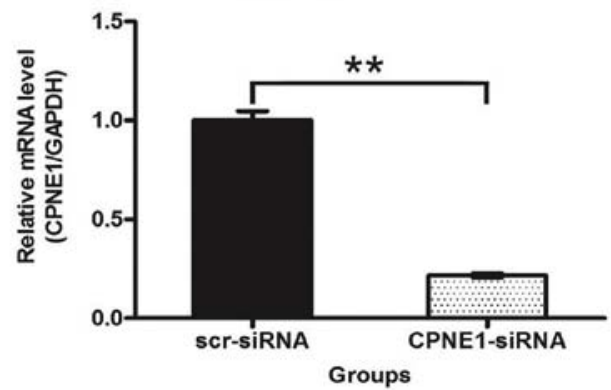

HOS cells

SCr- CPNE1SIRNA SIRNA

CPNE1

GAPDH

Figure 1. Analysis of CPNE1 expressions and lentivirus infection in osteosarcoma cells. (A) Immunohistochemical analysis of the expression of CPNE1. Immunohistochemical analysis of CPNE1 protein expression in osteosarcoma (a) and cartilage tumor tissues (b) (magnification, $\mathrm{x} 400$ ). (B) Lentivirus infection in osteosarcoma cells. Green fluorescence in the cell indicates the successful lentivirus-based delivery of siRNA into Saos-2 and HOS cells (magnification, x400). (C) The CPNE1 mRNA expression level was quantified by real-time RT-PCR. CPNE1 siRNA significantly decreased the level of $C P N E 1$ mRNA in Saos-2 and HOS cells. (D) The CPNE1 protein expression level was assessed by western blotting. CPNE1 siRNA significantly decreased the level of CPNE1 protein in Saos- 2 and HOS cells; ${ }^{* *} \mathrm{P}<0.01$, in comparison to the scr-siRNA group.

CPNE1 expression at the high level. Therefore a small portion of the cells kept proliferating. MTT assay was performed to investigate the effect of CPNE1 silencing on osteosarcoma cell growth. As shown in Fig. 2B, HOS cells showed a significant $(\mathrm{P}<0.01)$ reduction in viability 2 days after infection. The results suggest that $\mathrm{CPNE} 1$ silencing inhibits the proliferation of osteosarcoma cells.

The results of the colony formation assay showed that the number of colonies in the CPNE1-siRNA group (25.00 \pm 2.65$)$ was significantly less than that in the scr-siRNA group $(62.33 \pm 2.08)$ in the Saos- 2 cells $(\mathrm{P}<0.01)$, and the number of

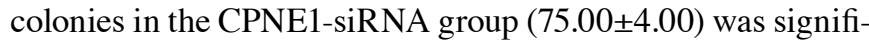
cantly less than that in the scr-siRNA group $(106.70 \pm 8.62)$ in the HOS cells $(\mathrm{P}<0.01)$ (Fig. $2 \mathrm{C})$. These results showed that the reduction in CPNE1 expression decreased the ability of osteosarcoma cells to form colonies.
siRNA-mediated CPNE1 knockdown inhibits the invasion and migration of osteosarcoma cells. As shown in Fig. 3A and B, in the Transwell invasion assay, the number of invading Saos-2 cells was $13.00 \pm 1.73$ in the CPNE1-siRNA group, which was significantly less than that in the scr-siRNA group $(27.33 \pm 1.53$; $\mathrm{P}<0.01$ ), and the number of invading HOS cells was $36.00 \pm 1.00$ in the CPNE1-siRNA group, which was significantly less than that in the scr-siRNA group $(229.30 \pm 2.31 ; \mathrm{P}<0.01)$. As shown in Fig. $3 \mathrm{C}$ and $\mathrm{D}$, in the Transwell migration assay, the number of migrating Saos-2 cells was $25.67 \pm 1.16$ in the CPNE1-siRNA group, which was significantly less than that in the scr-siRNA group $(79.00 \pm 2.65 ; \mathrm{P}<0.01)$. The number of migrating $\mathrm{HOS}$ cells was $12.00 \pm 2.00$ in the CPNE1-siRNA group, which was significantly less than that in the scr-siRNA group (88.00 \pm 1.00 ; $\mathrm{P}<0.01)$. The result showed that $C P N E 1$ silencing suppressed invasion and metastasis of osteosarcoma cells. 
A
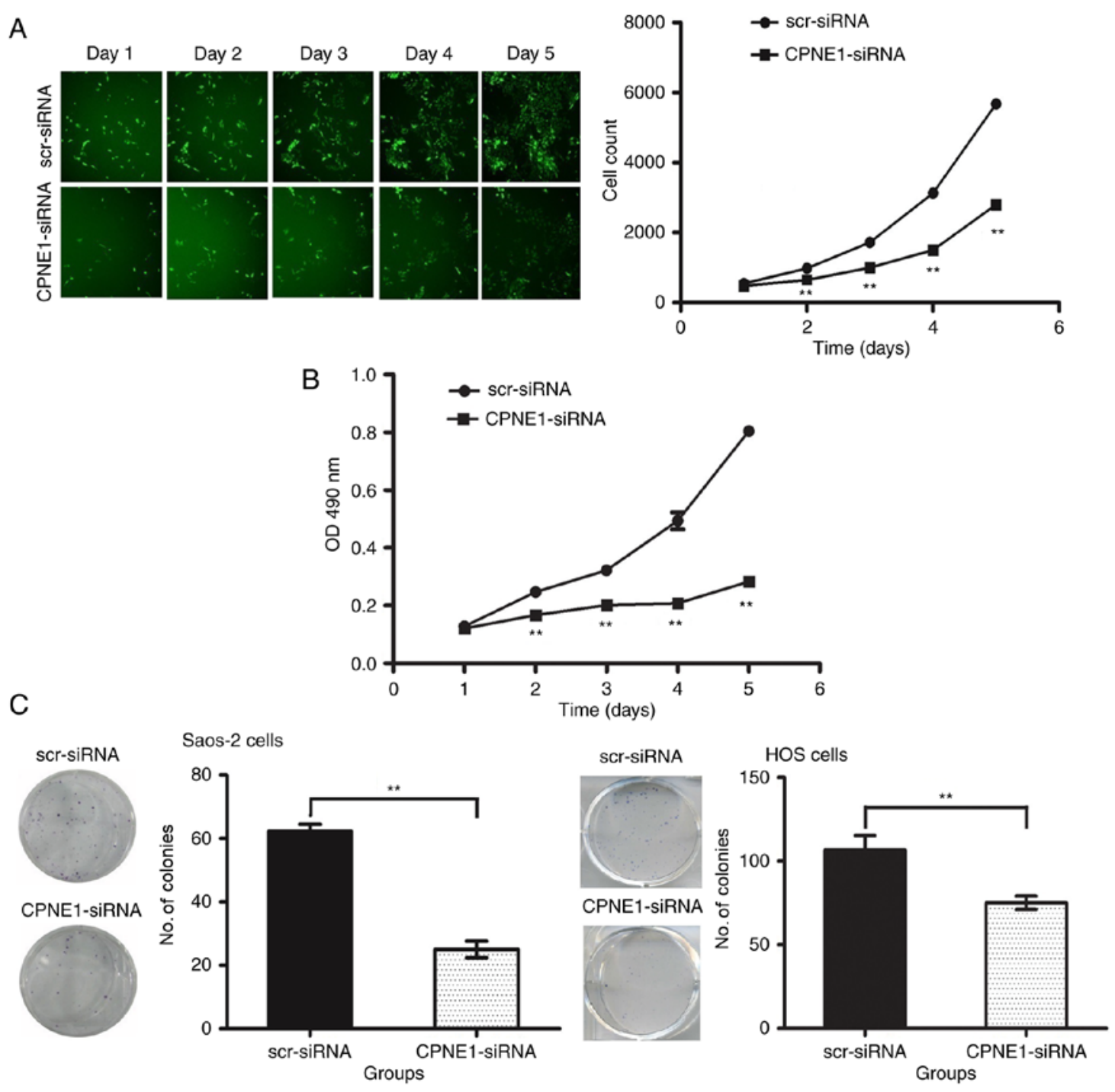

Figure 2. Effect of CPNE1 silencing on the proliferation of osteosarcoma cells. (A) Cellomics ArrayScan assay. The results showed that CPNE1 siRNA depressed the growth curves of Saos-2 cells as compared with the scr-siRNA with a time-dependent relationship. (B) MTT assay. The proliferation levels were measured by MTT assay in CPNE1-silenced and non-silenced HOS cells. CPNE1 siRNA depressed the growth curves of Saos-2 cells as compared with the scr-siRNA group. (C) Colony formation assay. The results showed that CPNE1 siRNA decreased the colony numbers of Saos-2 and HOS cells as compared with the scr-siRNA groups; ${ }^{*} \mathrm{P}<0.05,{ }^{* *} \mathrm{P}<0.01$, in comparison to the scr-siRNA group.

CPNE1 silencing leads to alterations in the cell cycle of Saos-2 cells. To elucidate the mechanisms underlying RNAi-mediated growth inhibition, flow cytometric analysis of the DNA content was used to detect the changes in the cell cycle. As shown in Fig. 4A-a and -b, CPNE1-siRNA treatment resulted in an increase in the percentage of Saos-2 cells in the $\mathrm{G} 2 / \mathrm{M}$ phase from $13.38 \pm 0.51$ to $18.01 \pm 0.63 \%(\mathrm{P}<0.01)$. In accordance with this increase in the percentage of cells in the $\mathrm{G} 2 / \mathrm{M}$ phase, there was a significant decrease in the percentage of cells in the $S$ phase from $34.04 \pm 0.89$ to $26.67 \pm 0.66 \%$ $(\mathrm{P}<0.01)$. CPNE1-siRNA treatment also resulted in an increase in the percentage of cells in the $\mathrm{G} 0 / \mathrm{G} 1$ phase from $52.57 \pm 0.42$ to $55.32 \pm 0.27 \%(\mathrm{P}<0.01)$. These results suggested that $\mathrm{CPNE} 1$ depletion inhibited the proliferation of osteosarcoma cells through $\mathrm{G} 2 / \mathrm{M}$ and $\mathrm{G} 0 / \mathrm{G} 1$ phase arrest of the cell cycle in Saos-2 cells.

Suppression of CPNE1 affects the expression of related proteins. To test the possible mechanisms underlying the inhibitory effects of CPNE1 knockdown on the biological functions of Saos-2 cells, the expression of various related proteins was examined. The results revealed that $C P N E 1$ knockdown downregulated Ras, MEK-1/2, WNT1, $\beta$-catenin, cyclin A1, cIAP2 and IRAK2 in the Saos-2 cells. These results suggest that the inhibitory effects on the biological functions associated with CPNE1 downregulation may be partly mediated by these related proteins in Saos-2 cells (Fig. 4B). Certainly, it is not clear whether these results are due to actions at the transcriptional or translational or both levels. Thus, further research is needed to elucidate the underlying molecular mechanism.

CPNE1 silencing sensitizes Saos-2 cells to chemotherapeutic agents. The effect of CPNE1 silencing on the sensitivity of Saos-2 cells towards DDP and ADR was determined. As shown in Fig. 4C (a and b), the $\mathrm{IC}_{50}$ for DDP in the CPNE1-siRNA group was $0.494 \pm 0.008 \mu \mathrm{g} / \mathrm{ml}$ at $72 \mathrm{~h}$, which was significantly less than that in the scr-siRNA 
A
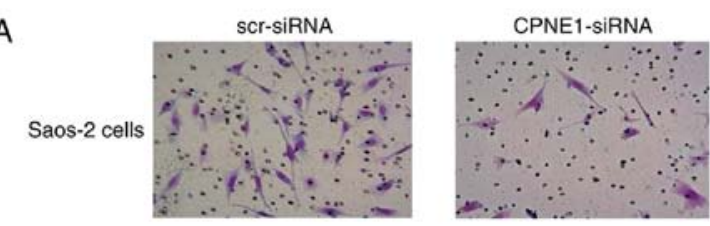

B

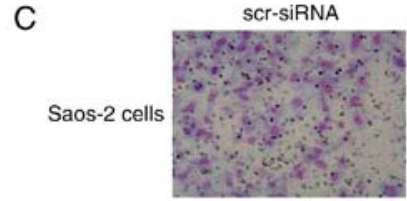

D

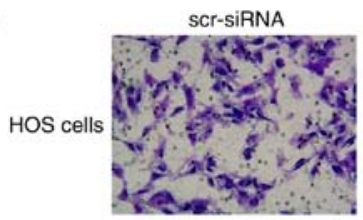

Scr-siRNA
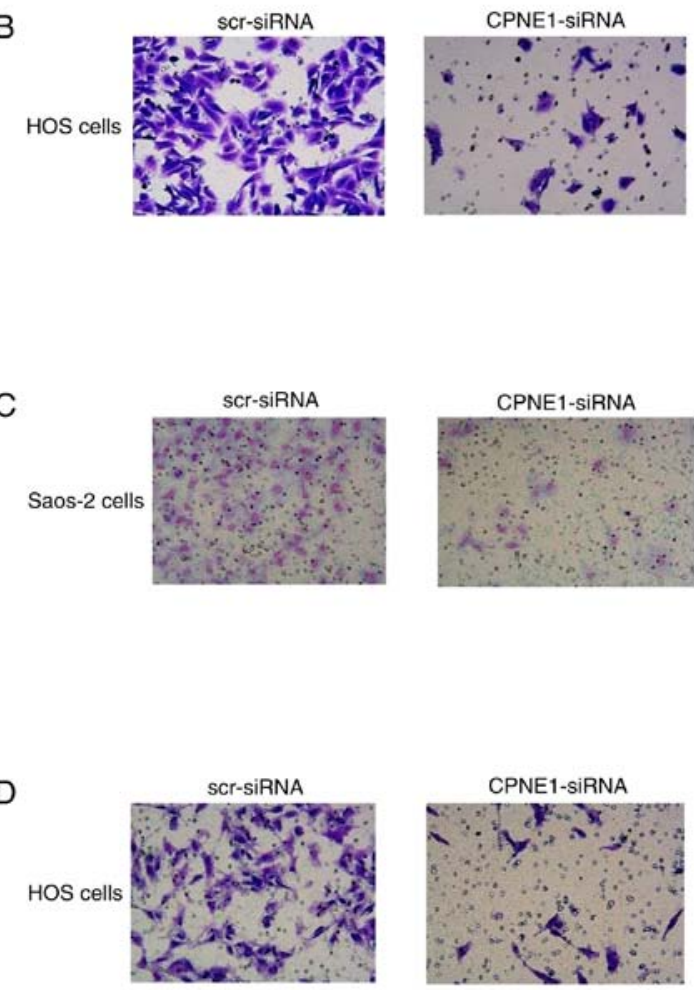
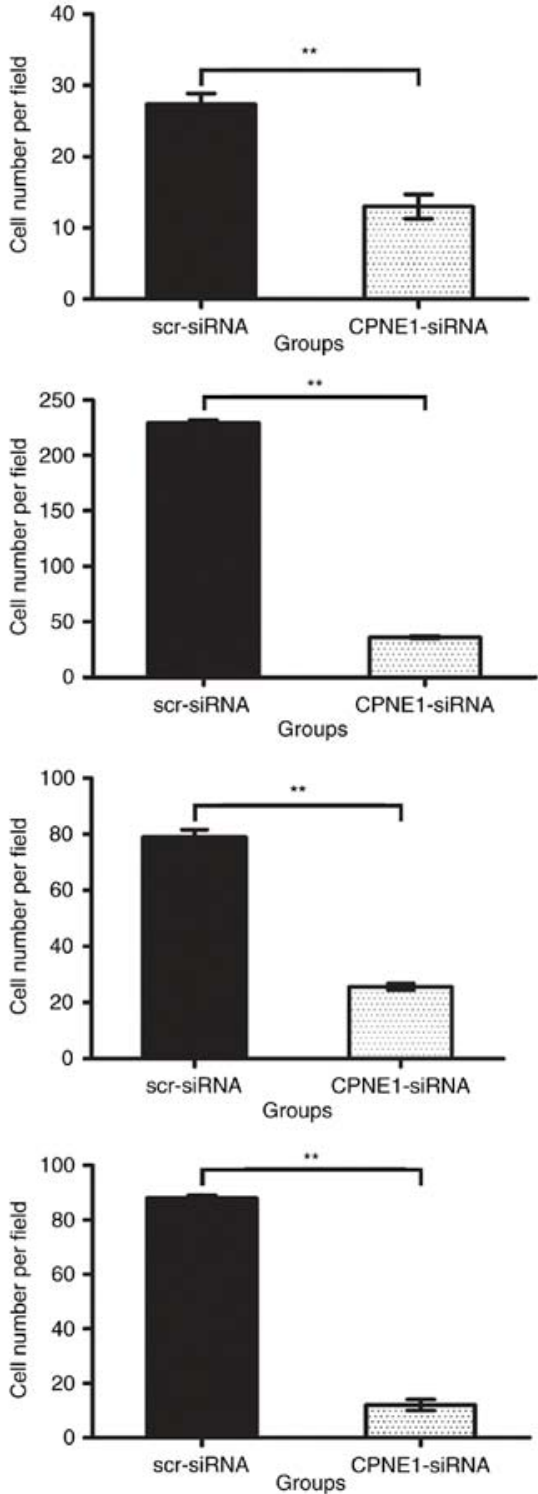

Figure 3. Effects of the inhibition of CPNE1 on the migration and invasion of osteosarcoma cells (magnification, x200). (A and B) Effects of CPNE1 siRNA on the invasion of osteosarcoma cells. Matrigel invasion assays of Saos-2 and HOS cells were performed. The quantified data are shown in the diagram. (C and D) Effects of CPNE1 siRNA on the migration of osteosarcoma cells. Migration assays of Saos-2 and HOS cells were performed. The quantified data are shown in the diagram. Inhibition of CPNE1 decreased osteosarcoma cell migration and invasion; ${ }^{* *} \mathrm{P}<0.01$ compared to the scr-siRNA group cells.

group $(0.832 \pm 0.030 \mu \mathrm{g} / \mathrm{ml} ; \mathrm{P}<0.01)$; the $\mathrm{IC}_{50}$ for $\mathrm{ADR}$ in the scr-siRNA group was $0.265 \pm 0.025 \mu \mathrm{g} / \mathrm{ml}$ at $72 \mathrm{~h}$, which was significantly less than that in the CPNE1-siRNA group $(0.619 \pm 0.066 \mu \mathrm{g} / \mathrm{ml} ; \mathrm{P}<0.01)$. These results suggested that Saos-2 cells could be effectively chemosensitized by siRNA-mediated CPNE1 silencing.

\section{Discussion}

CPNE1 is a highly conserved protein and is ubiquitously expressed in various tissues (6), but its biological function is not well known. In the present study, we observed that CPNE1 is highly expressed in osteosarcoma tissue, which indicates that CPNE1 may play an important role in the development of osteosarcoma.

We also found that CPNE1 silencing inhibited the proliferation, migration and invasion of Saos-2 and HOS cells. In addition, CPNE1 knockdown caused cell cycle arrest in the
G2/M and G0/G1 phases in the Saos-2 cells. Yet, not only cell cycle analysis, but also other important mechanisms (apoptotic or necrotic cell death) are needed to be investigated in the future. All these results provide direct evidence that CPNE1 may serve as a target for osteosarcoma treatment.

To elucidate the mechanisms underlying the function of CPNE1 in osteosarcoma, the expression of several related proteins was examined. Ras is a membrane-bound GTP-binding protein that functions as a molecular switche to transduce various signals from the cell membrane to the nucleus. Activated Ras recruits and activates Raf kinase at the plasma membrane. Activated Raf subsequently activates mitogen-activated protein kinase/ERK kinase MEK-1/2, which in turn phosphorylates and activates ERK1/2. Next, activated ERK1/2 regulates various cellular processes $(13,14)$. The RAS/RAF/MEK/ERK signaling pathway is one of the most important oncogenic pathways, which plays a central role in the regulation of cell proliferation and survival. This pathway is 
A a
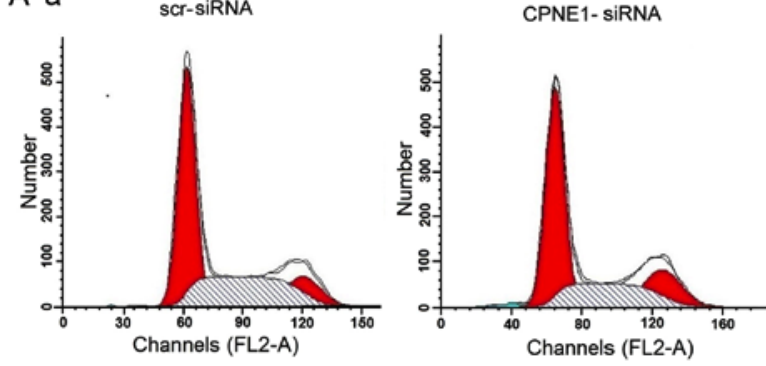

b

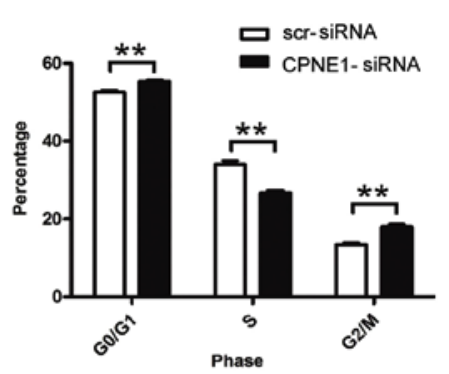

B

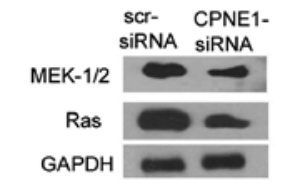

C a

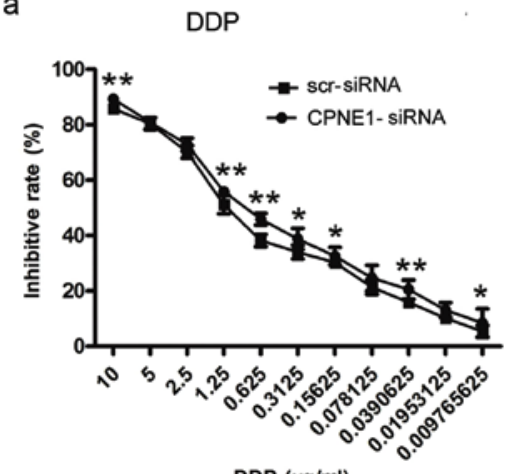

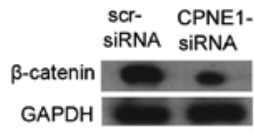

DDP $(\mu \mathrm{g} / \mathrm{ml})$

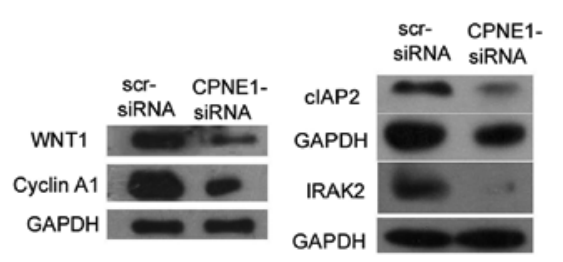

b

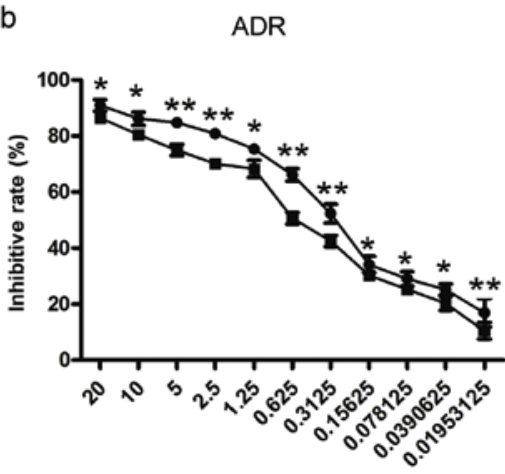

ADR $(\mu \mathrm{g} / \mathrm{ml})$

Figure 4. Flow cytometry, western blotting and chemosensitivity assay. (A) The effects of CPNE1 siRNA on the cell cycle distribution of osteosarcoma cells was determined by flow cytometric analysis: (a) the flow cytometric histogram and the number of cells under each phase of the cell cycle in CPNE1-silenced and non-silenced Saos-2 cells; (b) the numerical representation of the cells under each phase of the cell cycle in CPNE1-silenced and non-silenced Saos-2 cells. (B) Western blot analysis of the protein levels of related molecules. CPNE1 silencing downregulated Ras, MEK-1/2, WNT1, $\beta$-catenin, cyclin A1, IRAK2 and cIAP2 expression in Saos-2 cells. (C) Effect of CPNE1 knockdown on the chemosensitivity of Saos-2 cells: (a) effect of CPNE1 gene silencing on the chemosensitivity of Saos-2 cells to DDP; (b) effect of CPNE1 gene silencing on chemosensitivity of Saos-2 cells to ADR. Silencing of CPNE1 gene expression by siRNA significance enhanced the chemotherapeutic sensitivity of Saos- 2 cells; ${ }^{*} \mathrm{P}<0.05,{ }^{* *} \mathrm{P}<0.01$, in comparison to the scr-siRNA group.

aberrantly activated in various malignancies (15). Oncoprotein $\beta$-catenin, which is normally localized in the cytoplasm, funtions as an important transcriptional co-activator and transmits extracellular signals for the activation of certain target genes in the canonical Wnt pathway $(16,17)$. WNT1 binds to the target cell surface receptors of the Frizzled (Fzd) family to activate several different intracellular signal transduction pathways, resulting in $\beta$-catenin accumulation and nuclear translocation. Nuclear $\beta$-catenin induces the expression of downstream target genes, such as E-cadherin, c-Myc, and cyclin D1 (18-20). Cyclin A1 is highly expressed in cancers of the ovary, breast, lung and prostate (21-24). cyclin A1 is associated with the enhanced proliferation and invasiveness of various types of cancers (25-28). Inhibitor of apoptosis proteins (IAPs) are widely expressed in human tumor tissues and play an important role in cell apoptosis (29). Among these, cellular IAP2 (cIAP2) indirectly regulates apoptosis by preventing the formation of caspase-8-activating platform and blocking Smacmediated XIAP-caspase interaction $(30,31)$. Interleukin 1 receptor-associated kinase 2 (IRAK2) plays a critical role in sustaining NF- $\mathrm{kB}$ activation during TLR-mediated signaling, and IRAK2 overexpression activates NF-кB (32-34).
Notably, all the above factors, including Ras, MEK-1/2, WNT1, $\beta$-catenin, cyclin A1, cIAP2 and IRAK2, were downregulated after $C P N E 1$ knockdown, which indicated that the inhibition of the proliferation, migration, and invasion of human osteosarcoma cells after CPNE1 silencing is through downregulation of these factors. Further experiments may be essentially performed in future research.

Cisplatin (DDP) is a first-line chemotherapeutic agent that is widely used in various types of cancers, including those of the lung, bladder, cervix, ovary, endometrium and testicles $(35,36)$. Its cytotoxic effects are mediated by interaction with cellular DNA to form DNA adducts, which activates several signal transduction pathways, and culminates in the activation of cell apoptosis (37). Adriamycin (ADR) is also a first-line chemotherapeutic drug in the treatment of various types of cancers and induces DNA damage by topoisomerase II inhibition and free radical generation as an anticancer mechanism $(38,39)$.

To further confirm the synergistic effects of CPNE1 inhibition with typical cancer chemotherapeutic drugs on the suppression of osteosarcoma cell proliferation, we treated Saos-2 cells with different doses of the two chemotherapeutic drugs (DDP and ADR) combined with CPNEl knockdown. The results showed 
that $C P N E 1$ knockdown enhanced the suppression of effects of these two drugs on Saos- 2 cell proliferation. This is the direct evidence that $C P N E 1$ depletion could be combined with firstline chemotherapeutic drugs for treating osteosarcoma.

In conclusion, the present study firstly demonstrated that RNAi-mediated CPNE1 downregulation inhibited the proliferation and metastatic potential of osteosarcoma cells, and reduced expression of various tumor-related genes. In addition, blocking CPNE1 expression enhanced the chemosensitivity of osteosarcoma cells. However, the molecular mechanism of CPNE1 is complex, and further detailed studies and clinical trials are required.

\section{Acknowledgements}

The present study was supported by a grant from the Natural Science Foundation for the Youth (Beijing, China) (no. 81402220).

\section{References}

1. Ando K, Heymann MF, Stresing V, Mori K, Rédini F and Heymann D: Current therapeutic strategies and novel approaches in osteosarcoma. Cancers 5: 591-616, 2013.

2. Perry JA, Kiezun A, Tonzi P, Van Allen EM, Carter SL, Baca SC, Cowley GS, Bhatt AS, Rheinbay E, Pedamallu CS, et al: Complementary genomic approaches highlight the PI3K/mTOR pathway as a common vulnerability in osteosarcoma. Proc Natl Acad Sci USA 111: E5564-E5573, 2014.

3. Maugg D, Rothenaigner I, Schorpp K, Potukuchi HK, Korsching E, Baumhoer D, Hadian K, Smida J and Nathrath M: New small molecules targeting apoptosis and cell viability in osteosarcoma. PLoS One 10: e0129058, 2015.

4. Tomsig JL and Creutz CE: Copines: A ubiquitous family of $\mathrm{Ca}(2+)$-dependent phospholipid-binding proteins. Cell Mol Life Sci 59: 1467-1477, 2002.

5. Maitra R, Grigoryev DN, Bera TK, Pastan IH and Lee B: Cloning, molecular characterization, and expression analysis of Copine 8 . Biochem Biophys Res Commun 303: 842-847, 2003.

6. Creutz CE, Tomsig JL, Snyder SL, Gautier MC, Skouri F, Beisson $\mathrm{J}$ and Cohen J: The copines, a novel class of $\mathrm{C} 2$ domaincontaining, calcium-dependent, phospholipid-binding proteins conserved from Paramecium to humans. J Biol Chem 273: 1393-1402, 1998.

7. Perestenko PV, Pooler AM, Noorbakhshnia M, Gray A, Bauccio C and Jeffrey McIlhinney RA: Copines- $1,-2,-3,-6$ and -7 show different calcium-dependent intracellular membrane translocation and targeting. FEBS J 277: 5174-5189, 2010.

8. Tomsig JL, Snyder SL and Creutz CE: Identification of targets for calcium signaling through the copine family of proteins. Characterization of a coiled-coil copine-binding motif. J Biol Chem 278: 10048-10054, 2003.

9. Tomsig JL, Sohma H and Creutz CE: Calcium-dependent regulation of tumour necrosis factor-alpha receptor signalling by copine. Biochem J 378: 1089-1094, 2004.

10. Hwang LH: Gene therapy strategies for hepatocellular carcinoma. J Biomed Sci 13: 453-468, 2006.

11. Follenzi A and Gupta S: The promise of lentiviral gene therapy for liver cancer. J Hepatol 40: 337-340, 2004.

12. Zielske SP and Stevenson M: Importin 7 may be dispensable for human immunodeficiency virus type 1 and simian immunodeficiency virus infection of primary macrophages. J Virol 79: 11541-11546, 2005.

13. Rocks O, Peyker A and Bastiaens PI: Spatio-temporal segregation of Ras signals: One ship, three anchors, many harbors. Curr Opin Cell Biol 18: 351-357, 2006.

14. Campbell SL, Khosravi-Far R, Rossman KL, Clark GJ and Der CJ: Increasing complexity of Ras signaling. Oncogene 17 (11 Reviews): 1395-1413, 1998.

15. Prior IA, Lewis PD and Mattos C: A comprehensive survey of Ras mutations in cancer. Cancer Res 72: 2457-2467, 2012.

16. Kim W, Kim M and Jho EH: Wnt/ $\beta$-catenin signalling: From plasma membrane to nucleus. Biochem J 450: 9-21, 2013.
17. Clevers $\mathrm{H}$ and Nusse $\mathrm{R}$ : Wnt/ $\beta$-catenin signaling and disease. Cell 149: 1192-1205, 2012.

18. Sasaya K, Sudo H, Maeda G, Kawashiri S and Imai K: Concomitant loss of p120-catenin and $\beta$-catenin membrane expression and oral carcinoma progression with E-cadherin reduction. PLoS One 8: e69777, 2013.

19. He TC, Sparks AB, Rago C, Hermeking H, Zawel L, da Costa LT, Morin PJ, Vogelstein B and Kinzler KW: Identification of $c-M Y C$ as a target of the APC pathway. Science 281: 1509-1512, 1998.

20. Tetsu O and McCormick F: Beta-catenin regulates expression of cyclin D1 in colon carcinoma cells. Nature 398: 422-426, 1999.

21. Arsenic R, Braicu EI, Letsch A, Dietel M, Sehouli J, Keilholz U and Ochsenreither S: Cancer-testis antigen cyclin A1 is broadly expressed in ovarian cancer and is associated with prolonged time to tumor progression after platinum-based therapy. BMC Cancer 15: 784, 2015.

22. Shames DS, Girard L, Gao B, Sato M, Lewis CM, Shivapurkar N, Jiang A, Perou CM, Kim YH, Pollack JR, et al: A genome-wide screen for promoter methylation in lung cancer identifies novel methylation markers for multiple malignancies. PLoS Med 3: e486, 2006.

23. Syed Khaja AS, Dizeyi N, Kopparapu PK, Anagnostaki L, Härkönen $\mathrm{P}$ and Persson JL: Cyclin A1 modulates the expression of vascular endothelial growth factor and promotes hormone-dependent growth and angiogenesis of breast cancer. PLoS One 8: e72210, 2013.

24. Wegiel B, Bjartell A, Ekberg J, Gadaleanu V, Brunhoff C and Persson JL: A role for cyclin A1 in mediating the autocrine expression of vascular endothelial growth factor in prostate cancer. Oncogene 24: 6385-6393, 2005.

25. Ji P, Agrawal S, Diederichs S, Bäumer N, Becker A, Cauvet T, Kowski S, Beger C, Welte K, Berdel WE, et al: Cyclin A1, the alternative A-type cyclin, contributes to G1/S cell cycle progression in somatic cells. Oncogene 24: 2739-2744, 2005.

26. Kim J, Kim WJ, Liu Z, Loda M and Freeman MR: The ubiquitin-specific protease USP2a enhances tumor progression by targeting cyclin A1 in bladder cancer. Cell Cycle 11: 1123-1130, 2012.

27. Marlow LA, von Roemeling CA, Cooper SJ, Zhang Y, Rohl SD, Arora S, Gonzales IM, Azorsa DO, Reddi HV, Tun HW, et al: Foxo3a drives proliferation in anaplastic thyroid carcinoma through transcriptional regulation of cyclin A1: A paradigm shift that impacts current therapeutic strategies. J Cell Sci 125: 4253-4263, 2012

28. Wegiel B, Bjartell A, Culig Z and Persson JL: Interleukin-6 activates PI3K/Akt pathway and regulates cyclin A1 to promote prostate cancer cell survival. Int J Cancer 122: 1521-1529, 2008.

29. Hoeller D and Dikic I: Targeting the ubiquitin system in cancer therapy. Nature 458: 438-444, 2009.

30. Vucic D, Dixit VM and Wertz IE: Ubiquitylation in apoptosis: A post-translational modification at the edge of life and death. Nat Rev Mol Cell Biol 12: 439-452, 2011.

31. Vandenabeele P and Bertrand MJ: The role of the IAP E3 ubiquitin ligases in regulating pattern-recognition receptor signalling. Nat Rev Immunol 12: 833-844, 2012.

32. Rhyasen GW and Starczynowski DT: IRAK signalling in cancer. Br J Cancer 112: 232-237, 2015.

33. Lin SC, Lo YC and Wu H: Helical assembly in the MyD88-IRAK4-IRAK2 complex in TLR/IL-1R signalling. Nature 465: 885-890, 2010.

34. Kawagoe T, Sato S, Matsushita K, Kato H, Matsui K, Kumagai Y, Saitoh T, Kawai T, Takeuchi O and Akira S: Sequential control of Toll-like receptor-dependent responses by IRAK1 and IRAK2. Nat Immunol 9: 684-691, 2008.

35. Wang D and Lippard SJ: Cellular processing of platinum anticancer drugs. Nat Rev Drug Discov 4: 307-320, 2005.

36. Teng ZY, Cheng XL, Cai XT, Yang Y, Sun XY, Xu JD, Lu WG, Chen J, Hu CP, Zhou Q, et al: Ancient Chinese formula Qiong-Yu-Gao protects against cisplatin-induced nephrotoxicity without reducing anti-tumor activity. Sci Rep 5: 15592, 2015.

37. Siddik ZH: Cisplatin: Mode of cytotoxic action and molecular basis of resistance. Oncogene 22: 7265-7279, 2003.

38. Lee K, Qian DZ, Rey S, Wei H, Liu JO and Semenza GL: Anthracycline chemotherapy inhibits HIF-1 transcriptional activity and tumor-induced mobilization of circulating angiogenic cells. Proc Natl Acad Sci USA 106: 2353-2358, 2009

39. Mizutani H, Tada-Oikawa S, Hiraku Y, Kojima M and Kawanishi S: Mechanism of apoptosis induced by doxorubicin through the generation of hydrogen peroxide. Life Sci 76: $1439-1453,2005$. 